\title{
The Endowed Progress Effect: How Artificial Advancement Increases Effort
}

\author{
JOSEPH C. NUNES \\ XAVIER DREZE*
}

\begin{abstract}
This research documents a phenomenon we call the endowed progress effect, whereby people provided with artificial advancement toward a goal exhibit greater persistence toward reaching the goal. By converting a task requiring eight steps into a task requiring 10 steps but with two steps already complete, the task is reframed as one that has been undertaken and incomplete rather than not yet begun. This increases the likelihood of task completion and decreases completion time. The effect appears to depend on perceptions of task completion rather than a desire to avoid wasting the endowed progress. Moderators include the reason, if any, offered for the endowment and the currency in which progress is recorded.
\end{abstract}

$\mathrm{C}$ onsumers often persist in their efforts to achieve goals that are accompanied by discrete, extrinsic rewards. For example, they might delay purchasing a cellular phone a determinate number of months in order to get the newest product with the latest features. They might forgo various small discretionary purchases in order to save enough money to buy a big-ticket item such as a plasma TV. Or they might steer multiple purchases toward a particular air carrier with the hope of earning enough miles for a free flight. The notion that goals motivate individuals, making them work harder and perform better than people without goals, has been supported broadly in the literature (Locke and Latham 1990).

This research documents a phenomenon we call the endowed progress effect, whereby people provided with artificial advancement toward a goal exhibit greater persistence toward reaching the goal. By artificial advancement, we are referring to moving someone toward a goal while simultaneously moving the goal away such that the task requirements and reward remain unchanged. For example, consider reframing a frequency program that requires eight purchases in order to earn a specific reward as a program requiring 10, but with two purchases awarded upon enrollment. Both programs require eight purchases and provide

*Joseph C. Nunes is associate professor of marketing, Marshall School of Business, University of Southern California, Los Angeles, CA 900890443 (jnunes@marshall.usc.edu). Xavier Drèze is assistant professor of marketing, the Wharton School of the University of Pennsylvania, Philadelphia, PA 19104-6340 (xdreze@ wharton.upenn.edu). The authors would like to acknowledge the following for providing helpful comments on earlier versions of this article: Nathan Novemsky, Sanjay Sood, and Marc Vanhuele. They also thank the editor, the associate editor, and the reviewers for their insights. Both authors contributed equally and are listed in inverse alphabetical order. the same reward, yet for two reasons, we expect those who receive the endowed progress to exert more effort.

First, by framing the task as one that has been undertaken and is incomplete rather than one not yet begun, we expect people to be more committed to completing the task. Zeigarnik (1927) demonstrated that interrupted or uncompleted actions engender a strong motivation to complete the action, and psychologists agree that once a person accepts a task, for whatever reason, he or she tends to stay on that course until the goal is achieved (Fox and Hoffman 2002). Second, according to the goal gradient effect (see Hull 1932), people who are closer to their goal should exert comparatively more effort. Hence, we expect the initial momentum provided by the endowed progress to be compounded as effort increases with each step taken toward the goal.

The concept of persistence as a component of goaldirected behavior has been an integral part of motivation research for decades. Two central paradigms in the literature seek to explain persistence and have formed the foundation for modern approaches. First, Atkinson's work on achievement motivation (1957) depends on two fundamental elements: inertial tendency and expectancy. Inertial tendency is a psychological analog to Newton's first law of motion. Just as motion instigated in the physical world persists indefinitely unless acted upon by external forces, Atkinson believed a goal-directed tendency would persist until satisfied. Hence, inertial tendency reflects persistence and must be taken into account when evaluating other aspects of motivation. Expectancy is determined by the likelihood of success and the perceived value of attaining the goal. As the distance from the goal decreases, both the desirability and the feasibility of completion are believed to increase (Atkinson and Birch 1974). Models in this tradition have been 
labeled expectancy-value models (see Klein [1991] for a review).

A second, similar perspective on persistence emerges from Lewin's (1935) notion of task tension, which posits that, as internal needs are aroused, individuals enter a state of tension that can only be relieved by an external goal. The goal's valence, or perceived desirability, reflects its ability to relieve the tension. Motivation is a function of need tension and object valence, which is inversely related to an equally important third factor-the psychological distance between the current state and the goal. Accordingly, similar to the predictions from expectancy models, the goal gradient effect (Hull 1932) states that the closer someone is to his or her goal, the more motivated they become. In other words, both expectancy-value models and task tension predict that persistence increases with proximity.

While these two paradigms differ in many respects, two common themes are important for this research. The endowed progress (20\% complete vs. $0 \%$ ) provides an illusion of progress: the illusion that the task has been undertaken and is incomplete rather than not yet begun. This illusion provides momentum that endures as people are motivated by the idea of finishing what one starts. This leads to our first hypothesis.

H1: Reframing a task such that people believe the task has been undertaken and is incomplete will increase peoples' commitment toward completing the task, even if the absolute distance from the goal-or the actual task-does not change.

While people may focus on the level of relative completion, they may also consider proximity to the goal $(80 \%$ remaining rather than $100 \%$ ). According to the goal gradient effect, people who perceive that they are closer to their goal should exert comparatively more effort. In a classic study demonstrating this effect, Hull (1932) timed rats running in a maze and found that the closer they were to food (the reward), the faster they ran. Brown (1948) attached harnesses to rats running toward food. When the rats were stopped at various points, the attachment measured the strength with which they were pulling on the harness. Rats that were stopped nearer to the food pulled harder than those that were stopped farther away. While the goal gradient effect has been documented in subsequent studies, including several involving human participants (e.g., Fenz and Epstein 1967; Losco and Epstein 1977), none that we know of has looked at how perceptions of progress might affect effort. Our second hypothesis refers to the goal gradient effect as it pertains to humans' perceptions of progress.

H2: As people perceive that they are progressing toward their goal, their effort will increase, and thus completion time will decrease. Endowed progress, which provides artificial advancement toward the goal, will exacerbate this effect.

We should point out that we limit ourselves to task goals, as opposed to learning or performance goals, such that an extrinsic reward is granted only upon successful completion of the task, and anything short would likely be construed as a failure.

One example of persistence in goal-directed activity that has received increasing attention in recent years is escalation. The notion of escalation deviates from the simple dictates of expectancy value in that, while there is a likelihood of success and a desired end state, future prospects seem dim for making gains or even covering losses. The two predominant explanations put forth for irrational escalation are self-justification (Festinger 1957) and prospect theory (Kahneman and Tversky 1979). The self-justification explanation says that people feel compelled to justify to themselves and to others that previous decisions were rational. This explanation has been advanced by Arkes and Blumer (1985), who argue that people fail to ignore sunk costs and continue investing because they do not want to appear wasteful to themselves and to others. Others claim a more cognitive explanation, arguing decisions are not a simple linear function of expectancy-value calculations. Prospect theory's $\mathrm{S}$-shaped value function implies individuals are risk averse in the domain of gains and risk seeking in the domain of losses. As previous investments reflect losses, each incremental loss seems less painful. The decision is thus framed as a decision between losses, where people prefer the risk of losing more money incrementally with a chance of reducing or recouping past losses to the certainty of losing the entire amount they have invested thus far.

One issue with these explanations is that the proportion of a budget already invested in a project and the degree to which a project is completed are often confounded, although the two are distinct notions. Garland and Conlon (1998, 2045) argue that "if individuals are motivated to complete what they start and if this motive gets stronger as one gets closer to completion, then project completion may be a driving force behind individuals' continued investment in projects that are already well underway." Boehne and Paese (2000) conducted a study where respondents were expected to explain the reasoning behind their decisions. When a project was close to being complete, a much higher percentage of participants recommended completion, even when economically unreasonable, despite having to justify their decision. The level of sunk cost, or previous investment, had no effect. Hence, it has been argued that sunk cost effects have less to do with what was spent or expended and more to do with how close the project is to completion. This leads to our third hypothesis.

H3: Persistence will depend on relative progress and not on the amount that would be lost by failing to continue.

Of course, we expect boundaries to exist for the endowed progress effect. Two moderators in particular are expected to affect the ability of endowed progress to increase peoples' expectations that they can reach a goal and thus receive a reward. The first moderator is the medium in which progress is demarcated. Hsee et al. (2003) demonstrated that inserting 
a medium can provide an "illusion of advantage," such that efforts bring large returns in the medium accumulated, but any advantage in the actual outcome is small or nonexistent. They attribute the medium maximization effect they observed to a psychological myopia, whereby decision makers pay too much attention to the effort-medium relationship as opposed to the medium-outcome relationship. They argue that since the medium (e.g., points) is inherently worthless, people should base decisions solely on the effort-reward relationship itself. People do not, however, and often maximize the effort-medium return when the payoff in the medium appears large. Accordingly, this leads us to our next hypothesis.

H4: When the endowed progress is issued in points, both the endowment and the return to effort appear more significant, and thus effort will increase.

The second potential moderator is the reason provided to consumers for the endowment. When no reason is provided, we expect more people to perceive the endowed progress as a marketing ploy designed to lure people into enrolling in a loyalty program. Indeed, according to the Persuasion Knowledge Model (Friestad and Wright 1994), when consumers recognize an agent's action as a tactic during a persuasion attempt, they may become wary of the marketer's intent and skeptical of the true benefits of the offering. However, when a reason is provided for the endowment, conflicted consumers may choose to participate, relying on the endowment to justify the decision to participate (Shafir, Simonson, and Tversky 1993). The idea that goals or motives can affect reasoning is well documented in the psychology literature (see Kunda [1990] for a review). And the reason can either be realistic or specious, as it has been shown that consumers often base choices on easily justified, cognitively available, yet trivial reasons (Brown and Carpenter 2000). This leads us to our fifth and final hypothesis.

H5: The endowed progress effect is more likely to operate when consumers are provided with a reason for the endowment, even if that reason is specious.

The remainder of this article is organized as follows. In study 1 , we test hypotheses 1 and 2 , using a field experiment that allows us to assess whether the effect is measurable above the noise of conflicting and complicating factors. In study 2 , we test hypothesis 3 . We show that the effects of endowed progress do not depend on the magnitude of the endowment, an explanation associated with classic sunk cost explanations of escalation. Instead, expectations regarding future effort appear to depend on the perception of project completion, or relative progress. In study 3 , we test hypotheses 4 and 5 and thus the two proposed boundaries to the effect: (1) the reason for the endowed progress and (2) in what currency the progress is denominated. The article concludes by pointing out some of the limitations of this re- search, offering some managerial implications and suggesting avenues for future research.

\section{STUDY 1}

In study 1, we collected data in a field experiment conducted at a professional car wash in a major metropolitan area. Customers were put into one of two conditions. On the second and third Saturday in April 2004, the car wash randomly distributed 300 loyalty cards. Half of those required 10 additional purchases (i.e., special stamps) in order to earn one free car wash. Each customer was provided a card with two stamps already affixed such that only eight more stamps were truly required (two of 10 stamps, or $20 \%$ progress). Customers were told the free stamps were part of a special promotion that day, and no customer inquired further. The other 150 cards required only eight car wash purchases and were distributed with no stamps attached (zero of eight stamps, or 0\% progress). During the next 9 months, each time a customer paid to have his car washed and presented the card, the proprietors provided a stamp that included the date of the visit.

\section{Results}

Each card that was redeemed for a free car wash was collected, and the dates of each of the eight visits and the final redemption date were recorded. A total of 80 cards were redeemed between June 5, 2004, and September 17, 2004 (no cards were redeemed after September 17), providing records for 720 visits. The redemption rate for those possessing a card requiring 10 purchases, yet endowed with two stamps, was $34 \%$ versus just $19 \%$ for those who possessed a card requiring a total of eight purchases. This difference is statistically significant $\left(\chi^{2}(1)=8.1, p<.01\right)$. This suggests that reframing the task as already begun increases persistence as demonstrated by the higher rate of completion, supporting hypothesis 1 . This difference occurred even though the absolute distance from the goal did not change.

To test hypothesis 2, we examined the number of days elapsed between car washes (i.e., interpurchase times) across conditions and across visits (see fig. 1). We find a main effect of condition such that those given cards requiring 10 car washes take, on average, 2.9 days less between visits $(F(1,636)=5.2, p<.05)$. Furthermore, the time between visits decreased by 0.5 days on average with each additional car wash purchased $(F(1,636)=18.38, p<.01)$. This decrease in time between car washes reveals how, consistent with the goal gradient effect, effort increased as one got closer to the reward. We do not find a statistically significant interaction between condition and the number of car washes purchased $(F(1,636)<1)$. In other words, the time between the first and second purchase is reduced for those provided two stamps, as are the times between subsequent purchases. This leads to a more profound goal gradient effect for those endowed with progress (support for hypothesis 2). A hazard rate model fitted on the time between car washes provided 


\section{FIGURE 1}

STUDY 1: CAR WASH VISITS

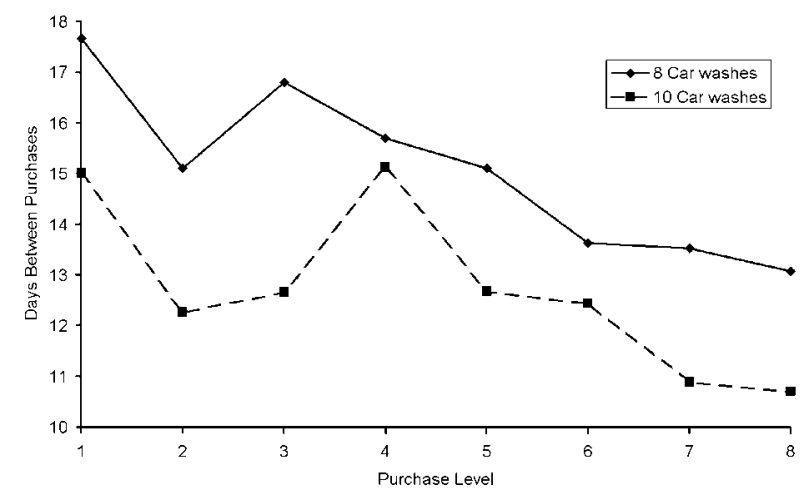

similar qualitative but stronger statistical results. We find a main effect of condition $\left(\chi^{2}(1)=9.97, p<.01\right)$ as well as level $\left(\chi^{2}(1)=27.85, p<.01\right)$, while their interaction was not statistically significant $\left(\chi^{2}(1)<1\right)$.

\section{Discussion}

In this real-world experiment, we show the impact of endowed progress on customer retention and usage rates. Providing patrons with endowed progress increased the number of customers who persisted or, conversely, reduced the number who abandoned the retailer. Those provided the endowed progress were more likely to buy the required eight car washes (hypothesis 1) and bought them sooner than their counterparts (hypothesis 2).

In study 2, we focus on two competing explanations for the perseverance we observe in study 1 that have been proposed to explain traditional sunk cost effects. The two predominant justifications are as follows: (1) people are reluctant either to waste or to appear to waste what they have already invested, as posited by Arkes and Blumer (1985), and (2) people are increasingly motivated to complete a task as they get closer to completion, as expounded by Garland and Conlon (1998). Perhaps respondents in the 10 car wash condition felt they would be giving up more by switching vendors and thus worked harder to avoid wasting the endowed progress (two vs. zero car washes). Alternatively, they may have focused on the perception of project completion, or relative progress, such that quitting after being two-tenths done (20\%) would feel worse than if they had not begun at all (being 0\% done). We test these hypotheses concurrently in study 2 .

\section{STUDY 2}

This study was designed to discern whether reluctance to waste, perceived progress, or both explanations jointly are responsible for observed endowed progress effects.

\section{Method}

Subjects. Participants were 146 undergraduate business students at a major West Coast university who participated in this along with several other studies for course credit.

Stimuli and Design. The design was a 2 (progress: onethird or one-sixth complete) $\times 2$ (endowment value: $\$ 12.50$ or $\$ 30.00$ ) between-subjects, full-factorial design with a separate control condition. To disentangle the competing explanations of wasted investment versus perceived progress, our design specifies a dollar value for the endowed progress.

Participants in this study completed a scenario-based, paper-and-pencil study. The study explained that a popular restaurant on campus was considering instituting a frequent buyer program. This study captures the essential decision making that likely occurs when consumers are confronted with enrolling in a frequency program, whether it requires signing up or just keeping the loyalty card in one's wallet. In the control surveys, customers had to purchases 10 lunches in order to earn a free lunch of identical value. Customers had not yet made any purchases, such that there was no progress toward their goal, real or perceived. There were four such scenarios that differed only in the required cost of each purchase $(\$ 2.50, \$ 6.00, \$ 6.25$, or $\$ 15.00)$. These studies provided a baseline measure. In the four scenarios that comprised the test conditions or cells, the amount of purchases required, the size of the endowment, and the cost of each purchase were each varied in order to manipulate perceived progress and endowment value simultaneously.

In two scenarios, participants were told that because they were first-time patrons they would receive two of 12 credits toward the reward (each credit worth the equivalent of one purchase in dollars), and, in the other two scenarios, they were told they would receive five of 15 credits, such that they were endowed with progress of one-sixth or one-third, respectively. These endowments manipulate the fraction of the task yet to complete; in the former, five-sixths must still be completed, and in the latter, only four-sixths remain. The dollar amount of a purchase varied and was crossed such that the total dollar value of the endowment was either $\$ 12.50$ or $\$ 30.00(5 \times \$ 2.50=2 \times \$ 6.25=\$ 12.50$, $5 \times \$ 6.00=2 \times \$ 15.00=\$ 30.00)$. See table 1 for a detailed summary of the design. Respondents were then asked how likely they would be to register for the program, how attractive they thought the program would be to diners, and how likely they would be to earn the reward on a nine-point scale. These measures served as the dependent variable.

\section{Results}

We conducted a test of reliability to ensure consistency across the three scales (likelihood of registering, attractiveness, and subjective likelihood of success within the program), which were intended to measure interest in the program (Cronbach's $\alpha=.80$ ). We then combined the individual scale values to derive a measure of overall im- 
TABLE 1

STUDY 2: RESULTS FOR PROGRAM IMPRESSIONS

\begin{tabular}{|c|c|c|c|c|c|c|}
\hline & & \multirow[b]{2}{*}{ Endowment } & \multicolumn{4}{|c|}{ Reward value } \\
\hline & & & $\begin{array}{l}\$ 2.50 \\
(A)\end{array}$ & $\begin{array}{l}\$ 6.00 \\
(\mathrm{~B})\end{array}$ & $\begin{array}{l}\$ 6.25 \\
(\mathrm{C})\end{array}$ & $\begin{array}{l}\$ 15.00 \\
\text { (D) }\end{array}$ \\
\hline (1) & $\begin{array}{l}\text { Interest } \\
n\end{array}$ & 0 & $\begin{array}{c}4.74(2.04) \\
19\end{array}$ & $\begin{array}{c}4.61(1.52) \\
19\end{array}$ & $\begin{array}{c}4.55(1.34) \\
17\end{array}$ & $\begin{array}{c}5.06(1.38) \\
18\end{array}$ \\
\hline (2) & $\begin{array}{l}\text { Interest } \\
n\end{array}$ & 2 & NA & NA & $\begin{array}{c}5.78(1.53) \\
18\end{array}$ & $\begin{array}{c}5.31(2.15) \\
18\end{array}$ \\
\hline (3) & $\begin{array}{l}\text { Interest } \\
n\end{array}$ & 5 & $\begin{array}{c}6.46(1.31) \\
18\end{array}$ & $\begin{array}{c}6.07(1.15) \\
19\end{array}$ & NA & NA \\
\hline (1) & Endowment value & 0 & 0 & 0 & 0 & 0 \\
\hline (2) & Endowment value & 2 & NA & NA & $\$ 12.50$ & $\$ 30.00$ \\
\hline (3) & Endowment value & 5 & 12.5 & 30 & NA & NA \\
\hline (1) & Progress & 0 & 0 & 0 & 0 & 0 \\
\hline (2) & Progress & 2 & NA & NA & $1 / 6$ & $1 / 6$ \\
\hline (3) & Progress & 5 & $1 / 3$ & $1 / 3$ & NA & NA \\
\hline
\end{tabular}

NotE.-For ease of exposition, each row and column is labeled. NA = not applicable. Standard deviations are in parentheses.

pression of the program, which we used as the dependent measure for our analyses.

We find evidence of an endowed progress effect as overall impression of the program increased as the endowment increased from zero to two to five $\left(M_{0}=4.74, M_{2}=5.55\right.$, $\left.M_{5}=6.26 ; F(2,143)=11.91, p<.01\right)$. In addition, individual comparisons suggest that an endowment in and of itself increases the overall evaluation. An endowment of two credits increases the evaluation $\left(M_{0}=4.74\right.$ vs. $M_{2}=5.55$, $p=.01)$, as does an endowment of five credits $\left(M_{0}=\right.$ 4.74 vs. $\left.M_{5}=6.26, p<.01\right)$. People's impressions might then depend on the two progress levels (one-sixth or onethird) as well as the dollar level of the endowment $(\$ 12.50$ or $\$ 30.00$ ). First, in order to determine whether perceptions of the value of the previous investment are driving the results, we compare cells B3 and D2 (\$30.00 endowments) to $\mathrm{A} 3$ and $\mathrm{C} 2$ (\$12.50 endowments) in table 1. We do not find any statistically significant difference, implying that the dollar amount of the endowment, whether $\$ 12.50$ or $\$ 30.00$, had no discernible effect on overall impression $(F(1,72)=$ $1.25, p=.27)$. This suggests that reluctance to waste, selfjustification, and other explanations of a sunk cost effect based on the absolute size of the investment made are not likely to be the underlying cause of the endowed progress effect.

Second, in order to determine whether perceptions of the relative progress made toward the goal are responsible for an increase in overall impressions, we compare cells A3 and B3 (progress of one-third) to cells C2 and D2 (progress of one-sixth), as shown in table 1 . We do find a statistically significant difference $(F(1,72)=3.79, p=.05)$, suggesting that people who are endowed with five of 15 purchases $\left(M_{1 / 3}=6.26\right)$ are more committed to joining the loyalty program than those endowed with two of 12 purchases $\left(M_{1 / 6}=5.55\right)$, even though everyone was required to make the same number of additional purchases to earn the reward
(10). Given these results, it appears that the endowed progress effect is the result of a change in perceived progress toward the goal, which supports hypothesis 3 .

\section{Discussion}

In study 1, we demonstrated the endowed progress effect. In study 2, we crossed the dollar value of the endowment (\$12.50 vs. \$30.00) with the relative progress that the endowment provides (one-third vs. one-sixth complete); this allowed us to discern that it is the relative progress and not the endowment's value that enhances people's overall impression with the proposed program. One limitation of study 2 is that it was hypothetical in nature and assessed people's likelihood of joining and predictions about completion rather than actual persistence. It is also important to note that no mention was made as to whether the endowment was a onetime bonus or might reoccur after consumers earned their first reward. Our intuition is that respondents saw this as a one-time bonus, and thus our scenarios compared perceptions of programs requiring 10 versus 12 versus 15 purchases. We view this as a conservative test because, presumably, a program with fewer necessary purchases would be seen as more attractive, which implies that the effect is strong enough to overcome this naturally occurring preference order. Study 3 was designed to test the boundaries of the effect (hypotheses 4 and 5).

\section{STUDY 3}

In study 3, we test the moderating effects of medium (whether the endowed progress is issued in purchases made or points) and the reason for the endowment (whether a reason is present and, if so, its realism). According to hypotheses 4 and 5 and because consumers are skeptical of typical marketing gimmicks, we expected the effect to be 
stronger when people are presented with a reason for the endowment (Friedsted and Wright 1994), and we expected the endowment to have a stronger effect when issued in an intervening currency due to medium maximization (Hsee et al. 2003).

\section{Method}

Subjects. Participants were 240 visitors to a local liquor store in a major metropolitan area. Only those who had shopped at that particular store at least once before were asked to participate. Before receiving the stimuli, they were asked to estimate their purchase history.

Stimuli and Design. The design was a 2 (medium: points or purchases) $\times 4$ (endowment: no endowment, endowment with no reason, endowment with specious reason, endowment with realistic reason) between-subjects, fullfactorial design. Shoppers were approached as they entered the store and asked if they would be willing to participate in a brief survey. Two hundred and forty people successfully completed the task, having been randomly assigned to one of the eight conditions.

Shoppers were told that the store they were about to enter was considering launching a frequent buyer program. Under the terms of the program, after purchasing 10 bottles of wine at a list price of $\$ 10$ or more, they would be entitled to one bottle priced up to $\$ 20$, free. When progress was recorded in points, they were told they would earn 10 points for each bottle of wine they purchased at a list price of $\$ 10$ or more and, after accumulating 100 points, they would be entitled to one bottle priced up to $\$ 20$, free. In the three endowment conditions (test), the required purchase amount was elevated to 15 bottles, or 150 points, with one bottle, or 10 points being issued for each bottle purchased costing $\$ 10$ or more. The number of purchases necessary was varied with the size of the endowment in order to keep the required number of future purchases constant at 10. Those in the conditions where respondents received an endowment and purchases were recorded in points (bottles) were told that after accumulating 150 points (15 bottles) they would be entitled to one bottle priced up to $\$ 20$, free. It was then explained that the store would credit their account with 50 points (five bottles) to start.

In the no reason condition, respondents were told simply that the store would credit their account with 50 points (five bottles) to start. In the other two endowment conditions, the reason for the endowment was varied such that participants were either told, "Because you are here today, the store would credit your account with five purchases to start" (i.e., a specious reason) or, "As someone with your purchase record, the store would credit your account with five purchases to start" (i.e., a realistic reason). A pretest confirmed that the realistic reason was viewed as more "plausible," "credible," and "realistic" and that it "makes sense" more than the specious reason (Cronbach's $\alpha=.81, M_{\text {pstpur }}=$ 5.06 vs. $\left.M_{\text {today }}=3.79, F(1,54)=46.15, p<.01\right)$.

All respondents were then asked how attractive they thought the program was on a seven-point scale, where seven indicated extremely attractive and one indicated not at all attractive. They were also asked how likely they would be to join the club and how likely they would be to buy 10 bottles in order to earn the reward $(7=$ extremely likely, $1=$ not at all likely).

\section{Results}

The dependent variables of attractiveness, likelihood of joining, and likelihood of reaching the goal (buying 10 bottles) were analyzed separately first to determine whether adoption and progress decisions differed. The results in terms of directional effects and their significance were identical. For ease of exposition, we collapsed all three scales into a singular measure of their overall evaluation of the program (Cronbach's $\alpha=.85$ ).

The results reveal a main effect of condition such that an endowment increased the overall evaluation of the program $(F(3,232)=111.00, p<.01)$. In addition, there was a main effect for medium $(F(1,232)=61.27, p<.01)$ and a significant interaction between the two $(F(3,232)=7.40$, $p<.01$, suggesting that tallying one's progress in points rather than purchases intensifies the endowed progress effect. Further, the interaction revealed the following interesting findings (see table 2).

When there is no endowment, it did not matter whether the medium was tallied in points or purchases $\left(M_{\mathrm{cntl}, \mathrm{pts}}=\right.$ 4.11 vs. $M_{\text {cntl,pur }}=4.06, p=.76$ ); the two groups were equally attracted to the program. In addition, when the endowment was tallied in purchases and no reason for the endowment was provided, the overall impression of the program was not significantly different from the no endowment condition $\left(M_{\text {no rsn,pur }}=4.24\right.$ vs. $\left.M_{\text {cntl, pur }}=4.06, p=.25\right)$. It seems that a reason is necessary to get an effect from the endowed progress when the monitoring base is purchases. Interestingly, when the endowment was delivered in points, overall impression increased significantly, even when no reason was provided for the endowment $\left(M_{\text {norsn,pts }}=4.79\right.$ vs. $\left.M_{\text {cntl,pts }}=4.11, p<.01\right)$. Therefore, recording purchases with an alternative currency allows the effect to occur with-

TABLE 2

STUDY 3: MEAN RESPONSES FOR COMMITMENT TO WINE STORE LOYALTY PROGRAM

\begin{tabular}{lccc}
\hline \hline & Points & Purchases & Average \\
\hline No reason & $4.79^{\mathrm{a}}$ & $4.24^{\mathrm{c}}$ & 4.52 \\
\multirow{2}{*}{ Specious reason } & $(.56)$ & $(.81)$ & \\
& $6.31^{\mathrm{b}}$ & $5.33^{\mathrm{d}}$ & 5.82 \\
Realistic reason & $(.56)$ & $(.54)$ & \\
& $6.19^{\mathrm{b}}$ & $5.20^{\mathrm{d}}$ & 5.70 \\
No endowment & $(.62)$ & $(.61)$ & \\
& $4.11^{\mathrm{c}}$ & $4.06^{\mathrm{c}}$ & 4.08 \\
Average & $(.54)$ & $(.78)$ & \\
\hline NoTE. & 5.35 & 4.71 & \\
other at $p \leq .01, n=30$ per with different superscripts are significantly different from each
\end{tabular}


out offering an explanation for the endowment. However, we should qualify this result by pointing out that providing a reason, whether specious or realistic, bolstered the average overall impression above what was achieved when no reason was provided.

Perhaps most interesting to marketing managers are the results of the specious reason condition. An entirely arbitrary reason was shown to work just as well as a reason based on purchase history for both points and purchases $\left(M_{\text {today,pts }}=\right.$ 6.31 vs. $M_{\text {pst pur,pts }}=6.19, p=.48 ; M_{\text {today,pur }}=5.33$ vs. $M_{\text {pst pur,pur }}=5.20, p=.42$ ). It appears that providing a reason, any reason, can aid the effectiveness of an artificial endowment. In short, when issuing unearned points, a reason is not necessary to get an effect, but any reason (specious or realistic) should increase the effectiveness of the endowment.

Finally, as mentioned earlier, the pattern of results was identical for each of the individual measures, with one measure being the subjective likelihood of buying 10 bottles of wine and therefore earning the reward. It is important to highlight that the pattern of results for this measure suggests that an endowed progress effect affects people's perceptions of the likelihood of success within a frequency program. In other words, endowing people with unearned progress (five bottles toward 15) leads them to believe they are more likely to complete the task than someone confronting an identical challenge (buying 10 bottles). This is consistent with previous research in the goal literature showing that rewards that require effort but seem attainable are motivating, while rewards acquired too easily appear gratuitous and are uninspiring.

\section{Discussion}

In study 3 , we again replicate the endowed progress effect, but in this study the effect is moderated by two important factors. First, the effect is more pronounced when the endowed progress is awarded in points rather than purchases. Second, the effect is magnified when offering a reason for the endowment, whether specious or realistic. A significant interaction reveals that, when the endowment is tallied in purchases, the effect occurs only when respondents are offered a reason for the artificial progress. However, when points become the monitoring base, no reason is necessary for the artificial endowment to have an effect.

Study 3 adds to our understanding of the endowed progress effect and its effectiveness as a marketing tool by highlighting critical factors the firm must consider when using endowed progress (e.g., special allotments of frequent flier miles) within a frequency program. It would seem that any program that monitors purchases will need to advise consumers up front as to why they are receiving an endowment advancing their progress toward a reward. We should point out that Cialdini's (1993) scarcity principle suggests that people assign more value to opportunities when they are less available, which would lead us to expect a greater effect in the realistic reason condition, when shoppers are selected because of past behavior rather than because they simply showed up at the store. Even though we do not observe any differences based on the type of reason provided, it may be that simply providing a reason, any reason, makes the endowment appear more difficult to attain and hence more valuable. A reason for the endowment is not necessary when progress is recorded in an alternative currency such as points, but in both cases a reason will further improve the overall impression of the program. The endowment has been shown to affect the attractiveness of a program, consumers' likelihood of joining, and their expectations of purchasing enough to earn the reward. In short, the endowed progress works best when a reason, even a seemingly arbitrary one, is offered for the endowment, and the effect is more profound when effort is recorded in an alternative currency or medium.

\section{GENERAL DISCUSSION}

This research documents a novel phenomenon, the endowed progress effect, in which people who are endowed with progress toward a goal increase the effort that they exert in reaching that goal. In study 1 , we document the phenomenon using a field experiment. Consumers endowed with progress (two of 10 purchases) were more likely to buy the required eight car washes and buy them sooner than those required to buy eight. In study 2 , the likelihood of joining a frequency program, the attractiveness of the program, and the subjective likelihood of completing the program requirements are all greater when a person is endowed with progress, even when the goal is elevated such that the effort required remains constant. In addition, this difference depends on a perception of progress toward the goal and does not appear to depend on the value of the endowment that would be wasted. Study 3 reveals how the effect can depend on the reason offered for the endowment. When there is no reason, the effect occurs only if the endowment is issued in an alternative currency such as points. However, when progress is recorded in purchases, even a specious reason such as one's presence at the store on a given day suffices to make the endowment effective.

One limitation of our studies is that, while study 1 allows us to document how effort accelerates, we observe effort only for those who bought all eight additional car washes. In study 2 , our measures serve to gauge how likely participants might be to join the program, which is what marketers are often most interested in. More generally, it would be interesting to determine how effort might change at different points of progress within a frequency program based on an endowment of artificial progress. The endowment may energize customers early on but wane over time (e.g., changed behavior in car wash patrons that we never observed). Also, while study 2 rules out a desire not to waste as a causal explanation for the endowed progress effect, it does so before genuine effort is expended. Perhaps the compounding of endowed and genuine progress would create an effect, one we may have observed in study 1 but did not measure in study 2 .

Another limitation of this work is that we focus solely 
on a single endowment. Firms that are interested in maximizing consumer lifetime value may be interested in methods for providing recurring endowments that are equally as effective. Just as discounts that are offered perpetually lose credibility among consumers, so might endowments of progress that seem to signal that neither the customer nor, perhaps, anyone else must acquire the benchmark amount of points in order to receive the reward. Future research may track the responsiveness to endowments both within a reward cycle and over time (across cycles) in order to see how consumers respond. It might also test what factors within the control of the firm affect the credibility of such endowments. One factor that would appear to affect the credibility of an endowment would be its size in absolute terms - and the corresponding reward level. For example, endowing someone with 90 of 100 purchases sets an unrealistic objective as well as endowment. These levels are likely to be idiosyncratic, varying with the specifics of a program.

Our results have several interesting implications with regard to the sunk cost effect and research investigating when and why people escalate commitment. For example, Heath (1995) suggests a budgeting model of escalating commitment, such that people create a mental budget to track costs and benefits and that additional investments will be made when the expected returns exceed the total (prior and current) investments. We show that this implicit break-even analysis can be affected by investments made on the consumer's behalf. However, our endowed progress does not serve to increase the benefit required to break even. Our experiments meet his requirement that people are confronted with identical marginal costs and marginal benefits, yet we show decisions changing based on whether an endowment is present or not. In this way, we not only offer evidence that the decision to escalate commitment can occur when marginal investments are identical and explicit, but we also show that decisions regarding escalation can be affected by investments that are artificial and outside of people's budgets.

The loss-sensitivity principle (Karlsson et al. 2002) suggests that prior investments will only have an effect when the goal is to minimize losses. In contrast, when the goal is to maximize gains, prior investments are ignored so that the decision is based on an evaluation of the future outcome. If rewards are viewed as net gains, our results would suggest that prior investments are not ignored when they indicate the relative progress made toward the final outcome. However, we may have observed a framing effect that deserves more attention in future research. On the one hand, expenditures recorded as purchases made (study 2) may focus people on the expense and hence make them think about the dollars they have spent. On the other hand, accumulating points may focus consumers on what they have acquired. The two scenarios might bring about different results that we believe are interesting yet only touched on in this research. We feel that this may present an attractive avenue for future work.
[Dawn Iacobucci served as editor and Stephen Nowlis served as associate editor for this article.]

\section{REFERENCES}

Arkes, Hal R. and Catherine Blumer (1985), "The Psychology of Sunk Cost," Organizational Behavior and Human Decision Processes, 35 (2), 124-40.

Atkinson, John W. (1957), "Motivational Determinants of RiskTaking Behavior," Psychological Review, 64 (November), 359-72.

Atkinson, John W. and David Birch (1974), "The Dynamics of Achievement-Oriented Activity," in Motivation and Achievement, ed. J. W. Atkinson and J. O. Raynor, Washington, DC: Winston, 271-325.

Boehne, Donna M. and Paul W. Paese (2000), "Deciding Whether to Complete or Terminate an Unfinished Project: A Strong Test of the Project Completion Hypothesis," Organizational Behavior and Human Decision Processes, 81 (2), 178-94.

Brown, Christina L. and Gregory S. Carpenter (2000), "Why Is the Trivial Important? A Reason-Based Account for the Effects of Trivial Attributes on Choice," Journal of Consumer Research, 26 (4), 372-85.

Brown, Judson S. (1948), "Gradients of Approach and Avoidance Responses and Their Relation to Level of Motivation," Journal of Comparative and Physiological Psychology, 41 (6), 450-65.

Cialdini, Robert B. (1993), Influence: Science and Practice, 3rd ed., New York: Harper Collins.

Fenz, Walter D. and Seymour Epstein (1967), "Gradients of Physiological Arousal of Experienced and Novice Parachutists as a Function of an Approaching Jump," Psychosomatic Medicine, 29 (1), 33-51.

Festinger, Leon A. (1957), A Theory of Cognitive Dissonance, Stanford, CA: Stanford University Press.

Fox, Shaul and Michael Hoffman (2002), "Escalation Behavior as a Specific Case of Goal-Directed Activity: A Persistence Paradigm," Basic and Applied Social Psychology, 24 (4), 273-85.

Friestad, Marian and Peter Wright (1994), "The Persuasion Knowledge Model: How People Cope with Persuasion Attempts," Journal of Consumer Research, 21 (1), 1-31.

Garland, Howard and Donald E. Conlon (1998), "Too Close to Quit: The Role of Project Completion in Maintaining Commitment," Journal of Applied Social Psychology, 28 (22), 2025-48.

Heath, Chip (1995), "Escalation and De-escalation of Commitment in Response to Sunk Costs: The Role of Budgeting in Mental Accounting," Organizational Behavior and Human Decision Processes, 62 (1), 38-54.

Hsee, Christopher K., Fang Yu, Jiao Zhang, and Yan Zhang (2003), "Medium Maximization," Journal of Consumer Research, 30 (1), 1-14

Hull, Clark L. (1932), "The Goal Gradient Hypothesis and Maze Learning," Psychological Review, 39 (1), 25-43.

Kahneman, Daniel and Amos Tversky (1979), "Prospect Theory: An Analysis of Decision under Risk," Econometrica, 47 (2), 263-91.

Karlsson, Niklas, Ásgeir Juliusson, Gunne Grankvist, and Tommy Gärling (2002), "Impact of Decision Goal on Escalation," Acta Pyschologica, 111 (3), 309-22.

Klein, Howard J. (1991), "Further Evidence on the Relationship between Goal-Setting and Expectancy Theory," Organizational Behavior and Human Decision Processes, 49 (2), 230-57. 
Kunda, Ziva (1990), “The Case for Motivated Reasoning," Psychological Bulletin, 108 (3), 480-98.

Lewin, Kurt (1935), A Dynamic Theory of Personality, New York: McGraw-Hill.

Locke, Edwin A. and Gary P. Latham (1990), A Theory of Goal Setting and Task Performance, Englewood Cliffs, NJ: PrenticeHall.

Losco, Jean and Seymour Epstein (1977), "Relative Steepness of
Approach and Avoidance Gradients as a Function of Magnitude and Valence of Incentive," Journal of Abnormal Psychology, 86 (4), 360-68.

Shafir, Eldar, Itamar Simonson, and Amos Tversky (1993), "ReasonBased Choice," Cognition, 49 (October-November), 11-36.

Zeigarnik, Bluma (1927), "Über das Behalten von erledigten und unterledigten Handlungen," Psychologische Forschung, 9 (1), $1-85$. 